\title{
PENILAIAN BEBERAPA SISTEM EVALUASI LAHAN YANG TELAH EKSISTING UNTUK TANAMAN KARET
}

\author{
The Assessment of Existing Land Evaluation Systems for Rubber Plantation \\ Priyo Adi NUGROHO dan ISTIANTO \\ Balai Penelitian Sungei Putih, Pusat Penelitian Karet \\ PO BOX 1415 Medan 20001 \\ e-mail: balitsp@indosat.net.id,priyo_adhie@yahoo.com
}

Diterima tanggal 29 April 2013 / Disetujui tanggal 5 September 2013

\begin{abstract}
For a successful agribusiness developmentone of the technical requirements is land suitability that needed prior evaluation before making any decision about rubber plantation. Some of these evaluation systems have been developed locally in Indonesia including Indonesian Rubber Research Institute by Pangudijatno in 1983 (GP), Sugiyanto in 1987 (SG), Sugiyanto et al. in 1998 (SE) and Thomas in 2008 (TW).The current research compared these land evaluation systems based on secondary data obtained from Indonesian Rubber Research Institute (IRRI) in eight locations across the country, consist of five land evaluation systems four from IRRI and one developed by Indonesian Soil and Agro Climate Research Institute in 1997 (PT). The correlation test result of $P T$ vs. GP and PT vs. TW showed the moderate correlation with coefficient 0.27 and 0.44 respectively. Strong level correlation reported in PT vs. SG, PT vs. SE, GP vs. SE, GP vs. $T W$ and SE $v$ s. SG with coefficient correlation 0.54, $0.63,0.63,0.72$ and 0.73 respectively. The correlation test in SG vs. GP, TW vs. SG and TW vs. SE showed very strong correlation with coefficient $0.76,0.77$ and 0.82 in all. The significant test applied to correlation test among five land evaluation systems where GP vs. SG, SG vs. TW and $S E$ vs. TW which display significant variance $(P<5 \%)$
\end{abstract}

Keywords: Hevea brasiliensis, existing land evaluation, correlation

\section{Abstrak}

Keberhasilan pengembangan agri-bisnis karet ditentukan oleh persyaratan teknis yaitu kesesuaian lahan yang sangat dibutuhkan sebelum pengambilan keputus-an. Beberapa sistem evaluasi lahan telah dikembangkan Pusat Penelitian Karet diantaranya oleh Pangudijatno tahun 1983 (GP), Sugiyanto tahun 1987 (SG), Sugiyanto et al. tahun 1998 (SE) dan Thomas Wijaya tahun 2008 (TW). Penelitian ini membandingkan beberapa sistem evaluasi lahan berdasarkan data sekunder dari Pusat Penelitian Karet pada delapan lokasi di seluruh Indonesia.
Sistem yang dibandingkan terdiri dari lima sistem empat diantaranya yang dikembangkan oleh Pusat Penelitian Karet dan satu dari Pusat Penelitian Tanah dan Agroklimat yang dikembangkan pada tahun 1997 (PT). Hasil uji korelasi menunjukkan bahwa PT vs. GP dan PT vs. TW menunjukkan korelasi sedang dengan nilai koefisien 0,27 dan 0,44. Korelasi yang kuat terjadi pada PT vs. SG, PT vs. SE, GP vs. SE, GP vs. TW and SE vs. SG dengan koefisien korelasi berturutturut 0,$54 ; 0,63 ; 0,63 ; 0,72$ dan 0,73. Uji korelasi antara SG vs. GP, TW vs. SG dan TW vs. SE menunjukkan korelasi yang sangat kuat dengan nilai koefisien 0,76, 0,77 dan 0,82. Dari seluruh uji korelasi antar beberapa sistem tersebut hanya uji korelasi GP vs SG, SG vs TW dan SE vs TW yang menunjukkan hasil yang signifikan $(\mathrm{P}<5 \%)$.

Kata kunci: Hevea brasiliensis, evaluasi lahan eksisting, korelasi

\section{PENDAHULUAN}

Prediksi IRSG (International Rubber Study group) yang menyebutkan bahwa sampai dengan tahun 2025 tingkat konsumsi karet alam dunia akan melebihi suplainya, telah berdampak pada meningkatnya minat pengusaha yang akan berinvestasi dalam usaha agribisnis karet (Damarjati dan Jacob, 2009). Walaupun dalam 3 tahun terakhir harga karet alam mengalami fluktuasi tetapi tidak menyurutkan minat investor untuk tetap mengusahakan komoditas ini.

Di sisi lain terbatasnya areal bagi peruntukkan Hak Guna Usaha (HGU) bagi agribisnis perkebunan, menyebabkan perkebunan karet bergeser ke areal dengan status kawasan hutan yang diakomodir dalam IUPHHK-HTI (Izin Usaha pemanfaatan Hasil Hutan Kayu-Hutan Tanaman Industri). Tidak semua areal di kawasan hutan sesuai untuk tanaman karet, 
beberapa persyaratan teknis yang berkaitan dengan lahan harus di evaluasi guna mendapatkan lingkungan yang mendukung bagi pertumbuhan tanaman karet (Nugroho, 2012).

Evaluasi lahan merupakan suatu pendekatan atau cara untuk menilai potensi sumber daya lahan. Hasil evaluasi lahan akan memberikan informasi dan/atau arahan penggunaan lahan yang diperlukan, dan akhirnya nilai harapan produksi yang kemungkinan akan diperoleh. Beberapa sistem evaluasi lahan telah banyak dikembangkan dengan menggunakan berbagai pendekatan, diantaranya sistem perkalian parameter, penjumlahan, dan sistem matching atau mencocokkan antara kualitas dan sifat-sifat lahan (Land Qualities/Land Characteritics) dengan kriteria kelas kesesuaian lahan yang disusun berdasarkan persyaratan tumbuh komoditas pertanian yang berbasis lahan (BBSDLP, 2011).

Beberapa sistem evaluasi lahan telah dikembangkan oleh Pusat Penelitian Karet diantaranya oleh Pangudijatno (1983) yang mengajukan penilaian lahan dengan sistem bertahap. Tahap pertama adalah penilaian terhadap iklim, apabila iklim sesuai dilanjutkan dengan penilaian kemampuan tanah yang terbagi dalam dua kelompok (fisiografi dan morfologi tanah).

Suatu usulan perbaikan mengenai sistem evaluasi lahan diajukan oleh Sugiyanto (1987), berdasarkan kesesuaian karakteristik iklim dan tanah. Dalam sistem tersebut, iklim dinilai berdasarkan 5 parameter yaitu ketinggian tempat, curah hujan, hujan pagi, kelembaban udara dan kecepatan angin. Faktor tanah yang dinilai berjumlah 7 parameter yaitu topografi, solum tanah, jumlah batuan di permukaan dan dalam tanah, drainase, tekstur tanah dan pH. Sama halnya dengan sistem Pangudijatno, parameter-parameter iklim dan tanah di sistem ini diberi nilai (scoring) untuk mengetahui kelas kesesuaian lahannya.

Setelah lebih dari satu dekade, usulan penyempurnaan dalam sistem evaluasi lahan untuk tanaman karet kembali diajukan oleh Sugiyanto et al., (1998). Faktor iklim yang semula berjumlah 5 parameter, berkembang menjadi 6 parameter yaitu dengan ditambahkan hari hujan dan bulan kering serta menghilangkan parameter kelembaban nisbi udara. Pada faktor tanah yang terdiri dari 7 parameter di reduksi menjadi 6 parameter dengan menghilangkan parameter jumlah batuan di permukaan dan di dalam tanah. Selain jumlah parameter, yang membedakan sistem ini dengan sistem sebelumnya adalah cara penentuan kelas kesesuaian lahannya. Penentuan kelas ditentukan dengan limitasi yang rasional yaitu mempertimbangkan kemampuan masing-masing parameter dalam mendukung pertumbuhan dan produktivitas tanaman.

Penyempurnaan sistem evaluasi lahan kembali diajukan oleh Thomas (2008), sistem ini banyak mengacu kepada sistem yang diajukan oleh Sugiyanto et al., 1998 dan RRIM (Rubber Research Institute of Malaysia). Curah hujan, bulan kering dan suhu udara merupakan 3 paramater iklim yang digunakan dalam sistem ini. Untuk faktor tanah parameter ketebalan lapisan gambut dan kedalaman lapisan sulfat mas a m d i a m b h k a n u t uk menyempurnakan parameter dalam faktor tanah yang digunakan dalam sistem evaluasi lahan Sugiyanto et al. (1998). Selain oleh Pusat Penelitian Karet, sistem evaluasi lahan juga dikembangkan oleh Pusat Penelitian Tanah dan Agroklimat (Puslittanak) yang juga mempertimbangkan aspek iklim dan tanah (Djaenudin et al., 1997).

Selain sistem penilaian yang berbeda, notasi yang digunakan pada beberapa sistem di atas juga sedikit berbeda. Penulisan notasi kelas kesesuaian lahan yang digunakan dalam sistem Pangudijatno (1983) berbeda dengan ke empat sistem lainnya. Dalam sistem tersebut lahan dengan tingkat kesesuaian lahan yang paling tinggi dinyatakan dengan "I" atau setara dengan "S1" pada keempat sistem lainnya. Lahan yang tidak sesuai dinyatakan dengan "IV" atau setara dengan "N" pada keempat sistem lainnya. Pada sistem Djaenudin et al. (1997) kelas lahan yang tidak sesuai dipecah menjadi "N1" yaitu lahan yang tidak sesuai saat ini dan "N2" yaitu lahan yang tidak sesuai permanen. 
Penelitian ini bertujuan untuk membandingkan serta melihat korelasi dari beberapa sistem evaluasi lahan untuk tanaman karet yang selanjutnya diharapkan dapat menjadi masukan dalam penyempurnaan sistem evaluasi lahan di masa mendatang.

\section{BAHAN DAN METODE}

Penelitian ini menggunakan data hasil survei dan evaluasi lahan, yang dilakukan oleh Pusat Penelitian Karet di delapan lokasi yang berbeda dan tersebar di beberapa wilayah Indonesia yaitu Sumatera Utara dengan kode NS, Sumatera Selatan dengan kode SS, Lampung dengan kode LP, Kalimantan Barat dengan kode WK, Kalimantan Timur dengan kode EK1 dan EK2, Kalimantan Selatan dengan kode SK, dan Pulau Seram dengan kode SI. Rekapitulasi data survei di delapan lokasi dan penilaian kesesuaian lahan disajikan dalam lampiran. Terdapat empat tahapan kegiatan dalam penelitian ini yaitu :

\section{Pengambilan data lapangan}

Pengambilan data lapangan baik berupa data primer maupun data sekunder dilakukan mengikuti prosedur Pusat Penelitian Karet dan bersamaan dengan kegiatan survei evaluasi lahan. Data-data seperti ketinggian tempat dan orientasi arah diambil dengan menggunakan GPS dan data kelerengan didapatkan dengan menggunakan klinometer. Pencandraan/deskripsi profil tanah hingga kedalaman $120 \mathrm{~cm}$ dilakukan untuk mengetahui kondisi morfologi tanah yang berkaitan dengan kriteria penilaian kesesuaian lahan untuk tanaman karet. Untuk keperluan analisis laboratorium pengambilan sampel tanah dilakukan pada kedalaman lapis olah (0-30 $\mathrm{cm})$ dengan menggunakan bor tanah maupun pada saat pencandraan profil. Data iklim selama 10 tahun berupa data curah hujan, hari hujan, suhu, kelembaban dan kecepatan angin diperoleh dari stasiun klimatologi yang terdekat dengan areal survei.

\section{Analisis tanah}

Sampel tanah yang telah diambil selanjutnya dibawa ke laboratorium untuk dianalisis sifat fisika maupun kimia tanahnya (Jackson, 1960). Sifat fisika tanah yang dianalisis yaitu tekstur tanah menggunakan metode pemipetan. Sifat kimia yang dianalisis meliputi KTK tanah dengan metode ekstraksi ammonium asetat, $\mathrm{pH}$ tanah $\mathrm{H}_{2} \mathrm{O}$ dengan $\mathrm{pH}$ meter, kandungan hara $\mathrm{N}$ dengan metode Kjedhal, kandungan hara $\mathrm{P}, \mathrm{K}$ dan $\mathrm{Mg}$ tersedia dengan metode kolorimetri serta $\mathrm{C}$-organik dengan metode Walkey and Black.

\section{Evaluasi lahan}

Evaluasi lahan/penilaian potensi lahan dilakukan di delapan lokasi survei berdasarkan data hasil pencandraan profil, data agroklimat dan data hasil analisa laboratorium di masing-masing lokasi dengan menggunakan lima sistem evaluasi lahan yaitu Pangudijatno, 1983 (GP), Sugiyanto, 1987 (SG), Djaenudin et al., 1997 (PT), Sugiyanto et al., 1998 (SE) dan Thomas, 2009 (TW)(lampiran).

\section{Analisis statistik}

Metode analisis korelasi spearman rank, digunakan dalam penelitian ini. Hasil evaluasi lahan dari kelima metode kemudian ditabulasi dan diberi ranking yang dimulai dari kelas kesesuaian lahan tertinggi, misalnya lahan dengan kelas kesesuaian "S1" beri nilai "1" , "S2" diberi nilai "2" dan seterusnya. Kelas kesesuaian lahan yang telah diperoleh untuk masing-masing sistem kemudian diurutkan berdasarkan kesesuaian lahan untuk tiap-tiap lokasi. Lokasi dengan kelas kesesuaian lahan yang paling sesuai diurutkan lebih dulu sehingga didapatkan ranking 1 sampai 8 yang selanjutnya disebut actual rank.

Jika dalam pengurutan diperoleh kelas yang sama maka ketiganya diberi ranking yang sama berdasarkan nilai rata-rata urutan (corrected rank). Sebagai contoh pada sistem GP (Tabel 1), SS, NS dan SS memiliki kelas kesesuaian lahan yang sama yaitu kelas I. corrected rank ditentukan dengan menjumlahkan SS, NS dan SS pada actual rank $(1+2+3)$ kemudian dibagi dengan 3 , sehingga corrected rank untuk masingmasing adalah "2".

Selanjutnya untuk mendapatkan korelasi antara dua metode (rs), data-data 
dianalisis dengan rumus :

$$
r s=1-\frac{6 \sum d^{2}}{n^{3}-n}
$$

Dimana :

rs $\quad=$ korelasi antar variable yang diuji (sistem evaluasi lahan),

$\mathrm{d}=$ Selisih ranking sampel (corrected rank),

$\mathrm{N}$ = Jumlah sampel (lokasi survei)

Uji signifikansi (uji P) dengan menggunakan bantuan software Genstat discovery $12^{\text {th }}$ version terhadap hasil penilaian sampel yang dilakukan dengan masing-masing sistem evaluasi lahan.

\section{HASIL DAN PEMBAHASAN}

Dalam kegiatan evaluasi lahan untuk komoditas pertanian, tanah dan iklim merupakan anasir utama yang menentukan tingkat kesesuaian lahan. Pada kelima sistem evaluasi lahan yang dianalisis, umumnya telah menggunakan kedua anasir tersebut sebagai parameter penilaian sehingga hasil penilaian setidaknya telah mengakomodasi persyaratan tumbuh tanaman karet dengan informasi lahan yang tersedia.

\section{Kesesuaian Lahan}

Hasil penilaian kesesuaian lahan pada delapan lokasi dengan menggunakan kelima sistem menunjukkan hasil yang berbeda. Hal yang menarik adalah pada sistem evaluasi PT dan SE beberapa lokasi dinyatakan sebagai lahan yang tidak sesuai (N; N1 maupun N2). Namun kondisi yang sama tidak terjadi pada ketiga sistem evaluasi lahan yang lain atau dengan kata lain mengapa dengan faktor pembatas yang sama tetapi tidak menghasilkan kesesuaian lahan yang sama pada sistem lain.

Dalam sistem evaluasi SE, pada lokasi EK1 dan WK digolongkan sebagai $\mathrm{N}$ karena terdapat dua pembatas berat pada parameter karakteristik tanah yaitu tekstur tanah dengan kandungan pasir $>70 \%$ dan status hara yang sangat rendah. Dalam sistem penilaian tersebut tersebut apabila terdapat $>\underline{2}$ pembatas berat maka lahan dikelompokkan menjadi tidak sesuai (N).

Kelas kesesuaian lahan WK pada sistem PT termasuk ke dalam N1 atau tidak sesuai untuk saat ini. Sistem PT menggunakan pendekatan limitasi sederhana yang artinya kesesuaian lahan sangat ditentukan oleh parameter yang paling membatasi. Dalam kasus ini karena

Tabel 1. Hasil evaluasi lahan dengan 5 sistem yang berbeda dan hasil pengkelasan

Table 1. The result of land evaluation using five systems and the rank

\begin{tabular}{|c|c|c|c|c|c|c|c|c|}
\hline \multirow{2}{*}{$\begin{array}{l}\text { Jenis sistem } \\
\text { Type of system }\end{array}$} & \multicolumn{8}{|c|}{$\begin{array}{l}\text { Kelas kesesuaian lahan } \\
\text { Land suitability class }\end{array}$} \\
\hline & EK1 & WK & SI & SK & $\mathrm{NS}$ & SS & LP & EK2 \\
\hline $\begin{array}{l}\text { GP system } \\
\text { Actual rank } \\
\text { Corrected rank }\end{array}$ & $\begin{array}{l}\text { III } \\
8 \\
8\end{array}$ & $\begin{array}{c}\text { II } \\
7 \\
5,5\end{array}$ & $\begin{array}{c}\text { II } \\
6 \\
5,5\end{array}$ & $\begin{array}{l}\mathrm{I} \\
1 \\
2\end{array}$ & $\begin{array}{l}\text { I } \\
2 \\
2\end{array}$ & $\begin{array}{l}\mathrm{I} \\
3 \\
2\end{array}$ & $\begin{array}{c}\text { II } \\
4 \\
5,5\end{array}$ & $\begin{array}{c}\text { II } \\
5 \\
5,5\end{array}$ \\
\hline $\begin{array}{l}\text { SG system } \\
\text { Actual rank } \\
\text { Corrected rank }\end{array}$ & $\begin{array}{l}\mathrm{S} 2 \\
7 \\
6\end{array}$ & $\begin{array}{l}\text { S3 } \\
8 \\
8\end{array}$ & $\begin{array}{c}\mathrm{S} 1 \\
1 \\
2,5\end{array}$ & $\begin{array}{c}\mathrm{S} 1 \\
2 \\
2,5\end{array}$ & $\begin{array}{c}\mathrm{S} 1 \\
3 \\
2,5\end{array}$ & $\begin{array}{c}\mathrm{S} 1 \\
4 \\
2,5\end{array}$ & $\begin{array}{l}\text { S2 } \\
5 \\
6\end{array}$ & $\begin{array}{l}\mathrm{S} 2 \\
6 \\
6\end{array}$ \\
\hline $\begin{array}{l}\text { PT system } \\
\text { Actual rank } \\
\text { Corrected rank }\end{array}$ & $\begin{array}{c}\mathrm{S} 3 \\
5 \\
3,5\end{array}$ & $\begin{array}{l}\mathrm{N} 1 \\
6 \\
6\end{array}$ & $\begin{array}{c}\mathrm{N} 2 \\
7 \\
7,5\end{array}$ & $\begin{array}{c}\mathrm{S} 2 \\
1 \\
1\end{array}$ & $\begin{array}{c}\text { S3 } \\
2 \\
3,5\end{array}$ & $\begin{array}{c}\mathrm{S} 3 \\
3 \\
3,5\end{array}$ & $\begin{array}{c}\mathrm{S} 3 \\
4 \\
3,5\end{array}$ & $\begin{array}{c}\mathrm{N} 2 \\
8 \\
7,5\end{array}$ \\
\hline $\begin{array}{l}\text { SE system } \\
\text { Actual rank } \\
\text { Corrected rank }\end{array}$ & $\begin{array}{c}\mathrm{N} \\
7 \\
7,5\end{array}$ & $\begin{array}{c}\mathrm{N} \\
8 \\
7,5\end{array}$ & $\begin{array}{c}\mathrm{S} 2 \\
4 \\
3\end{array}$ & $\begin{array}{c}\mathrm{S} 3 \\
5 \\
5,5\end{array}$ & $\begin{array}{c}\mathrm{S} 2 \\
3 \\
3\end{array}$ & $\begin{array}{c}\mathrm{S} 1 \\
1 \\
1\end{array}$ & $\begin{array}{l}\mathrm{S} 2 \\
2 \\
3\end{array}$ & $\begin{array}{c}\text { S3 } \\
6 \\
5,5\end{array}$ \\
\hline $\begin{array}{l}\text { TW system } \\
\text { Actual rank } \\
\text { Corrected rank }\end{array}$ & $\begin{array}{c}\text { S3 } \\
7 \\
7,5\end{array}$ & $\begin{array}{c}\text { S3 } \\
8 \\
7,5\end{array}$ & $\begin{array}{c}\mathrm{S} 1 \\
1 \\
3,5\end{array}$ & $\begin{array}{c}\mathrm{S} 1 \\
2 \\
3,5\end{array}$ & $\begin{array}{c}\mathrm{S} 1 \\
3 \\
3,5\end{array}$ & $\begin{array}{c}\mathrm{S} 1 \\
4 \\
3,5\end{array}$ & $\begin{array}{c}\mathrm{S} 1 \\
5 \\
3,5\end{array}$ & $\begin{array}{c}\text { S1 } \\
6 \\
3,5\end{array}$ \\
\hline
\end{tabular}


parameter slope menunjukkan kesesuaian yang paling rendah yaitu N1 maka kesesuaian lahannya jatuh ke dalam tidak sesuai untuk saat ini (N1). Hal yang sama juga terjadi pada lahan SI dan EK2 yang mana pada keduanya curah hujan yang rendah $1.440 \mathrm{~mm} /$ tahun dan slope yang melebihi $45 \%$ merupakan masing-masing faktor pembatas beratnya. Dengan demikian SI dan EK2 tergolong ke dalam N2 atau lahan tidak sesuai permanen.

Perlu dicermati bahwa dalam kelima sistem yang digunakan dalam tulisan ini memiliki prosedur yang berbeda dalam menentukan kesesuaian lahan suatu lokasi. Secara umum terdapat tiga metode penentuan kesesuaian lahan pada kelima sistem tersebut. Metode-metode tersebut yaitu (1) Scoring yang digunakan pada sistem evaluasi PG dan SG, (2) limitasi sederhana yang dipakai dalam sistem PT dan (3) Limitasi rasional yang digunakan pada sistem SE dan TW.

Dalam penentukan kesesuaian lahan menggunakan metode scoring faktor yang paling membatasi akan mengecil pengaruhnya karena tertutupi oleh score/nilai kumulatif dari keseluruhan faktor. Sebagai contoh dalam sistem SG di lokasi EK1, walaupun tekstur tanah dan status hara yang rendah merupakan faktor yang paling membatasi (berat) tetapi karena nilai kumulatifnya adalah 31 maka kesesuaiannya menjadi S2.

Metode limitasi sederhana terlihat pada sistem PT yang juga telah dijelaskan di atas. Pada metode ini faktor yang paling membatasi memiliki peranan yang dominan sehingga faktor lainnya dapat diabaikan.
Metode limitasi rasional yang juga telah dicontohkan di atas sedikit berbeda dengan metode limitasi sederhana. Di sini faktor yang paling membatasi tidak mendominasi dalam penentuan kesesuaian lahan. Penentuan kesesuaian lahan pada metode tersebut mengikuti aturan sebagai berikut; lahan dengan maksimal 1 pembatas medium adalah sangat sesuai (S1); lahan cukup sesuai (S2) adalah lahan yang memiliki maksimal 2 pembatas medium; Lahan dengan 2 atau lebih pembatas medium dan atau 1 pembatas berat tergolong lahan yang kurang sesuai/sesuai marginal (S3); lahan dengan 2 atau lebih pembatas berat adalah lahan yang tidak sesuai $(\mathrm{N})$.

\section{Korelasi Antar Sistem Evaluasi Lahan}

Berdasarkan hasil analisis statistik terhadap kelima sistem tersebut menunjukkan adanya korelasi yang positif antara masing-masing sistem. Hasil analisa statistik antara beberapa metode evaluasi lahan disajikan pada Tabel 2 di bawah ini. Korelasi yang positif menunjukkan bahwa terdapat kesesuaian antara kelima metode yang digunakan untuk menilai kelas kesesuaian lahan di delapan lokasi. Pada Tabel 1 terlihat bahwa terdapat nilai koefisien korelasi yang berbeda-beda, korelasi terkecil adalah 0,27 dan yang terbesar adalah 0,82. Di dalam teori statistik disebutkan bahwa korelasi yang sempurna apabila koefisien korelasinya medekati angka +1 atau -1 . Apabila nilai koefisiennya $0,75 \leq \mathrm{r} \leq 1$, hubungannya dinyatakan kuat dan searah. Jika nilai koefisiennya $-1 \leq r \leq-$ 0,75 dinyatakan hubungannya kuat dan berlawanan arah. Hubungan dua variabel dinyatakan lemah apabila korelasinya -0,75 $<\mathrm{r}<0,75$.

Tabel 2. Korelasi antar sistem evaluasi lahan

Table 2. Correlation among land evaluation system

\begin{tabular}{cccccc}
\hline & \multicolumn{5}{c}{ Korelasi antar sampel } \\
Sistemevaluasi lahan & \multicolumn{5}{c}{ Correlation among sample } \\
Land evaluation system & GP & SG & PT & SE & TW \\
\hline GP & 1 & & & & \\
SG & 0,76 & 1 & & & \\
PT & 0,55 & 0,43 & 1 & & \\
SE & 0,63 & 0,72 & 0,16 & 1 & \\
TW & 0,73 & 0,77 & 0,33 & 0,82 & 1 \\
\hline
\end{tabular}


Sarwono (2006), membagi hubungan korelasi menjadi 6 tingkatan sebagai berikut : Jika nilai koefisien korelasi $r=0$ maka dinyatakan tidak terdapat korelasi antara kedua variable, jika koefisien korelasi $0<\mathrm{r} \leq$ 0,25 dinyatakan berkorelasi sangat lemah, koefisien $0,25<r \leq 0,50$ dinyatakan berkorelasi cukup, apabila nilai koefisien 0,50< $r \leq 0,75$ dinyatakan berkorelasi cukup kuat, koefisien yang bernilai $0,75<\mathrm{r} \leq 1$ dinyatakan berkorelasi yang sangat kuat antar dua variabel, sedangkan $\mathrm{r}=1$ memiliki korelasi yang sempurna. Korelasi antar metode evaluasi lahan disajikan berikut ini :

\section{Korelasi cukup/sedang}

Hasil uji korelasi dengan menggunakan metode spearman rank, menunjukkan bahwa terdapat tiga hubungan korelasi dalam penelitian ini yaitu korelasi yang cukup/sedang, cukup kuat dan sangat kuat. Hasil uji korelasi antara metode PT vs SG dan metode PT vs TW menunjukkan hubungan korelasi yang cukup/sedang dengan nilai koefisien korelasi masingmasing sebesar 0,43 dan 0,33. Hal tersebut kemungkinan terjadi karena adanya perbedaan parameter penilaian kesesuaian lahan antara ketiga metode tersebut.

Dalam metode PT karakterisitik lahan (tanah dan iklim) yang digunakan berjumlah 30 jenis sedangkan dalam metode SG dan TW karakteristik lahan yang digunakan dalam penilaian masing-masing berjumlah 12 dan 11 jenis. Perbedaan lainnya adalah output penilaian, dimana pada metode PT terdapat 5 kelas kesesuaian yaitu $\mathrm{S} 1$ (sesuai), S2 (cukup sesuai), S3 (sesuai marginal), N1 (tidak sesuai namun tidak permanen) dan N2 (tidak sesuai permanen). Dalam metode SG dan TW kelas kesesuaian dibagi menjadi empat kelas yaitu S1 (sesuai), S2 (cukup sesuai), S3 (sesuai marginal), N (tidak sesuai).

\section{Korelasi cukup kuat}

Korelasi yang cukup kuat terlihat pada uji korelasi antara metode GP vs PT, GP vs SE, metode GP vs TW dan metode SE vs SG. Koefisien korelasi terendah terdapat pada pengujian antara PT dan GP yaitu sebesar 0,55 . Angka tersebut sebetulnya lebih mendekati ke arah hubungan korelasi yang sedang. Jika diamati metode GP sebenarnya memiliki kedekatan dengan metode SG, SE, TW, hal ini terlihat dari output penilaian yang berupa empat kelas kesesuaian walaupun berbeda notasinya namun memiliki substansi yang hampir sama. Dalam metode GP kelas kesesuaian lahan terdiri dari lahan kelas I (sesuai), II (cukup sesuai), III (sesuai marginal), IV (tidak sesuai). Dalam metode SG, SE dan TW kelas kesesuaian lahannya yaitu S1 (sesuai), S2 (cukup sesuai), S3 (sesuai marginal), N (tidak sesuai).

\section{Korelasi sangat kuat}

Korelasi yang sangat kuat terlihat pada uji korelasi antara metode SG vs GP, metode TW vs SG, dan metode TW vs SE dengan koefisien masing-masing sebesar 0,$76 ; 0,77$ dan 0,82 . Korelasi yang sangat kuat kemungkinan disebabkan oleh adanya pesamaan dalam hal output kelas kesesuaian lahan yang masing-masing terdiri dari 4 kategori. Selain itu semakin banyak jumlah karakteristik lahan yang sama dari beberapa metode turut mempengaruhi tingkat korelasi ke 4 metode tersebut. Sebagai contoh pada SE dan TW, enam dari delapan karakteristik lahan yang digunakan dalam metode TW sama dengan karakteristik lahan yang digunakan oleh metode SE. Pada SG vs TW walaupun banyak karakteristik lahan yang menunjukkan kesamaan namun karena metode penentuan kelas berbeda turut mempengaruhi nilai korelasi antara kedua metode, dalam penentuan kelas metode SG menggunakan Scoring sedangkan TW menggunakan limitasi yang rasional. Dalam SG dan GP terdapat kesamaan dalam cara penilaian yang keduanya menggunakan cara scoring, nilai koefisien yang lebih rendah dari TW vs SG dan TW vs SE diduga karena rentang yang digunakan untuk memberikan bobot di setiap karakteristik lahan pada metode GP lebih sempit daripada rentang yang digunakan dalam metode SG.

\section{Uji Signifikansi}

Uji signifikansi bertujuan untuk mengetahui tingkat korelasi yang dihasilkan antara setiap metode, signifikan atau tidak secara statistik. Dalam statistik pertanian secara umum kita menggunakan angka signifikansi sebesar 0,01 atau 0,05. Angka 
kepercayaannya adalah sebesar 95\%. suatu nilai dikatakan signifikan apabila tingkat kepercayaannya mencapai atau mendekati 95\%. Hasil uji signifikansi dari setiap metode disajikan pada Tabel 3 di bawah ini.

Dari Tabel 3. Dapat dilihat bahwa tidak semua hasil uji korelasi antar sistem evaluasi lahan signifikan, walaupun memiliki korelasi positif yang sedang hingga sangat kuat satu sama lainnya. Uji korelasi GP vs. SG dan SE vs. TW menunjukkan hasil yang signifikan pada taraf $5 \%$. Jika tingkat kepercayaan dinaikkan menjadi $97.5 \%$ (pada taraf 2,5\%) maka SE dan TW akan lebih signifikan. Dengan demikian kedua sistem evaluasi lahan yaitu SE dan TW masih relevan untuk digunakan dalam penilaian potensi lahan suatu daerah.

Tabel 3. Tingkat signifikansi antar sistem evaluasi lahan

Table 3. Significant level among land evaluation system

\begin{tabular}{cllll}
\hline $\begin{array}{c}\text { Sistem evaluasi lahan } \\
\text { Land evaluation system }\end{array}$ & GP & SG & PT & SE \\
\hline SG & $0,050^{*}$ & & & \\
PT & 0,241 & 0,427 & & \\
SE & 0,130 & 0,062 & 0,852 & \\
TW & 0,100 & 0,058 & 0,874 & $0,021^{*}$ \\
\hline
\end{tabular}

*) Signifikan pada taraf $5 \%$

\section{KESIMPULAN DAN SARAN}

Berdasarkan hasil kajian/uji korelasi dan signifikansi terhadap lima sistem evaluasi lahan dapat ditarik kesimpulan sebagai berikut :

1. Uji korelasi antara PT vs SG dan PT vs TW menunjukkan hubungan korelasi yang cukup/sedang dengan nilai koefisien korelasi masing-masing 0,43 dan 0,33 .

2. Hubungan korelasi yang cukup kuat terdapat pada pengujian GP vs PT, metode GP vs SE, metode GP vs TW dan metode SE vs SG dengan koefisien korelasi berturut-turut 0,55, 0,63,0,73 dan 0,72 .

3. Uji korelasi pada sistem SG vs GP, TW vs SG, dan TW vs SE menunjukkan korelasi yang sangat kuat dengan koefisien masing-masing sebesar 0,76, 0,77 dan 0,82 .

4. Dari seluruh uji korelasi antar beberapa sistem tersebut, GP vs SG dan SE vs TW yang menunjukkan hasil yang signifikan $(\mathrm{P}<5 \%)$.

5. Berdasarkan uji signifikansi maka dua sistem evaluasi lahan (SE dan TW) masih relevan untuk digunakan dalam mengevaluasi kesesuaian lahan untuk tanaman karet.

\section{DAFTAR PUSTAKA}

Adeyanju, A. and A.S. Fasina. 2007. Comparison of three land evaluation system in evaluating the predictive value of some selected soils in AdoEkiti, Southwest Nigeria. Nigerian J. Soil Science 17; 113-119.

BBSDLP. 2011. Kriteria kesesuaian lahan. Http:/ / bbsdlp.litbang.deptan.go.id diakses tanggal 1 April 2013.

Damardjati, D.S. and J. Jacob. 2009. Present trends and outlook for global supply of natural rubber. Dalam A. D. Sagala, N. Siagian, Istianto dan A. Rachmawan (eds.) Prosiding Lokakarya Nasional Pemuliaan Tanaman Karet 2009. Batam, 4-6 Agustus 2009.

Djaenudin, D., Marwan, Subagyo, dan A. Mulyani. 1997. Kriteria Kesesuaian Lahan untuk Komoditas Pertanian. Pusat Penelitian Tanah dan Agroklimat, Bogor.

Jackson, M.L. 1960. Soil Chemical Analysis. Prentice-Hall, Englewood Cliffs, New Jersey. USA. 
Nugroho, P.A. 2012 Pengembangan Agribisnis Karet Melalui Pengusahaan Hutan Tanaman Industri (HTI) Karet. Warta Perkaretan 31(2); 32-42.

Pangudijatno, G. 1983. Kriteria kesesuaian lahan untuk tanaman karet. Bulletin Perkaretan 2; 34-42.

Sugiyanto, Y. 1987. Suatu usulan untuk merevisi evaluasi lahan untuk tanaman karet. Warta Perkaretan (6) $1: 8-12$,

Sugiyanto, Y., Sihombing, H. dan Darmandono. 1998. Pemetaan agroklimat dan tingkat kesesuaian lahan perkebunan karet. Dalam Anwar, R, I. Suhendry, A. D. Sagala, M. Lasminingsih (eds.) Prosiding Konferensi Nasional Pemuliaan Tanaman Karet 1998 dan Diskusi Nasional tentang Prospek Karet Alam di Abad 21 Medan, 8-9 Desember .
Wijaya, T. 2008. Kesesuaian tanah dan agroklimat untuk tanaman karet. Warta Perkaretan 27(2) ; 34-44.

Sarwono, J. 2006. Metode Penelitian Kuantitatif dan Kualitatif. Graha Ilmu. Yogyakarta. 


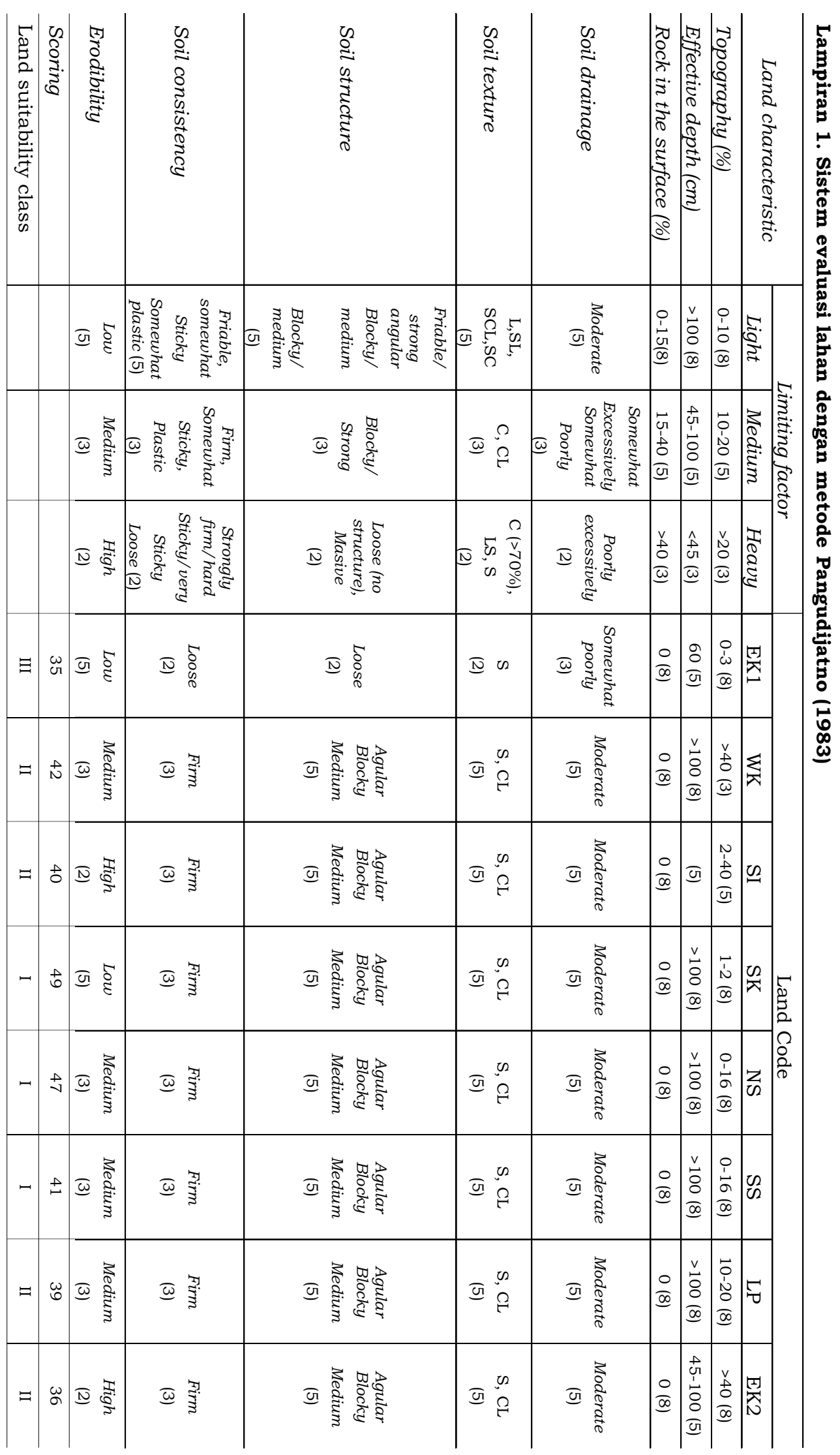




\begin{tabular}{|c|c|c|c|c|c|c|c|}
\hline 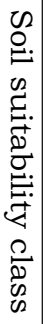 & 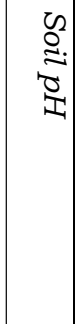 & 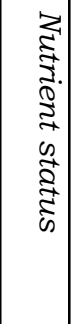 & 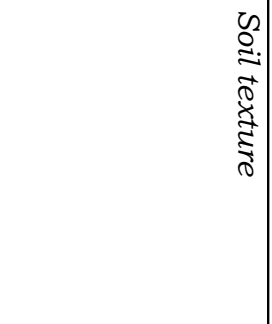 & 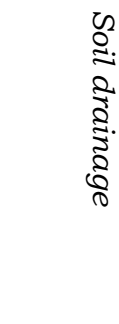 & 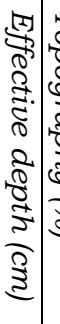 & 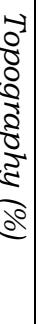 & 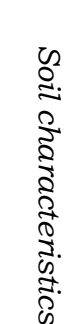 \\
\hline & $\begin{array}{l}+ \\
\omega \\
1 \\
0 \\
0\end{array}$ & 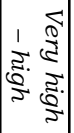 & 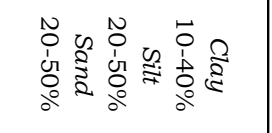 & 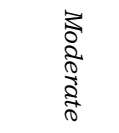 & $\begin{array}{l}v \\
\square \\
8\end{array}$ & $\begin{array}{l}0 \\
1 \\
a\end{array}$ & 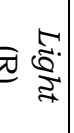 \\
\hline & $\begin{array}{l}0 \\
\hat{a} \\
1 \\
o \\
\text { or }\end{array}$ & $\mid$ & 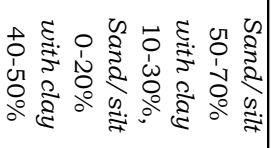 & 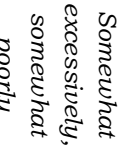 & $\mid \begin{array}{l}0 \\
e \\
1 \\
1 \\
8 \\
8\end{array}$ & $\begin{array}{l}0 \\
\vec{v} \\
\dot{0} \\
\overrightarrow{0}\end{array}$ & ב2: \\
\hline & $\begin{array}{l}\hat{p} \\
\dot{c} \\
v \\
o \\
\hat{o} \\
\hat{i}\end{array}$ & है & 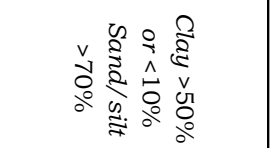 & 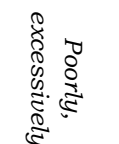 & $\begin{array}{l}\hat{f} \\
\text { vi }\end{array}$ & $\begin{array}{lll} & & \\
\vdots & 5 \\
0 & -5\end{array}$ & 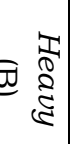 \\
\hline$z$ & $\overline{0} \vec{\omega}$ & 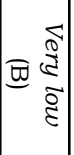 & 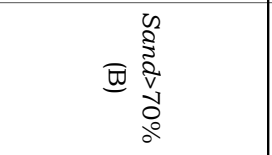 & 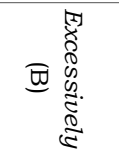 & $\begin{array}{l}\frac{\partial}{0} \\
\vec{\theta}\end{array} \mid$ & $\begin{array}{l}0 \\
\dot{\omega} \\
\pi \\
\text { t }\end{array}$ & 圆 \\
\hline$\stackrel{\omega}{\omega}$ & $\begin{array}{ll} & \overrightarrow{0} \\
& 0 \\
0 & 1 \\
0 & 0 \\
0 & 0\end{array}$ & त्र & 지 $\Omega_{\Omega}^{n}$ & चु & \begin{tabular}{|l}
$v$ \\
8 \\
8 \\
0
\end{tabular} & $\begin{array}{l}v^{v} \\
\text { D } \\
\text { 國 }\end{array}$ & ¿્ર \\
\hline $\mathscr{\omega}$ & त्र $\stackrel{+}{\alpha}$ & 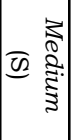 & 징 & 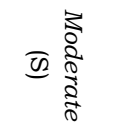 & $\left|\begin{array}{c}0 \\
0 \\
1 \\
0 \\
0 \\
0\end{array}\right|$ & $\begin{array}{l}n \\
\vdots \\
0 \\
\text { wa }\end{array}$ & $\Omega$ \\
\hline $\mathscr{W}$ & 지 $\stackrel{+}{-1}$ & $\left(\begin{array}{|cc}\varpi & 5 \\
\varepsilon\end{array}\right.$ & 지 & 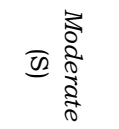 & $\mid$\begin{tabular}{|c|}
$v$ \\
$\vdots$ \\
0 \\
0 \\
0
\end{tabular} & 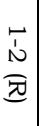 & $\stackrel{2}{2}$ \\
\hline$\stackrel{N}{N}$ & 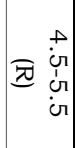 & 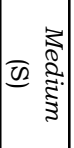 & 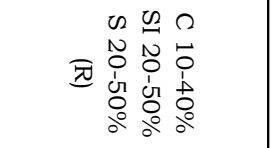 & 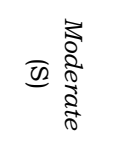 & $\mid \begin{array}{c}v \\
\overrightarrow{8} \\
\text { त्र }\end{array}$ & 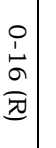 & $\begin{array}{l}z \\
\text { us }\end{array}$ \\
\hline $\mathscr{N}$ & $\begin{array}{ll} & + \\
0 & 0 \\
0 & \vdots \\
\text { in }\end{array}$ & क्ञ & 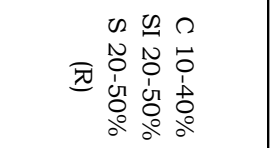 & च] & $\begin{array}{l}v \\
\vdots \\
0 \\
\vdots 0\end{array}$ & $\begin{array}{l}0 \\
\vdots \\
\sigma \\
\text { त्र }\end{array}$ & $\tilde{U}$ \\
\hline$\underset{N}{\sim}$ & 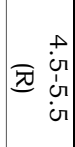 & चु & 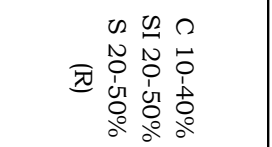 & च] & 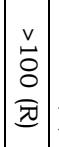 & $\begin{array}{l}\overrightarrow{0} \\
\text { N } \\
\text { त्र }\end{array}$ & 5 \\
\hline ¿ & त्र $\stackrel{\overrightarrow{0}}{\mathrm{c}}$ & 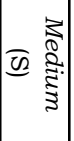 & 지 & 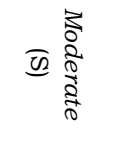 & $\left|\begin{array}{c}0 \\
0 \\
\vdots \\
0 \\
0 \\
\frac{2}{2}\end{array}\right|$ & $\begin{array}{l}\text { 品 } \\
\text { 囬 }\end{array}$ & 焉 \\
\hline
\end{tabular}

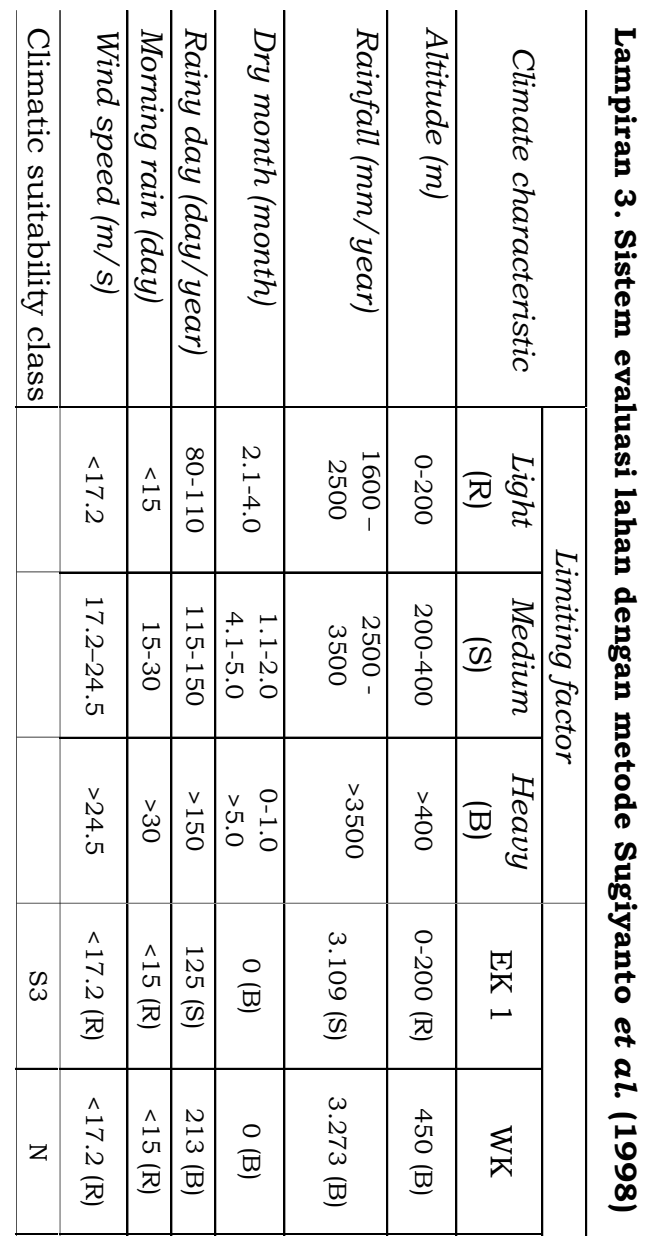

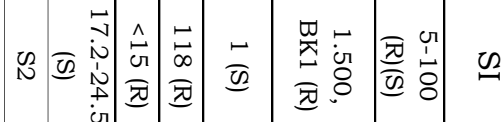

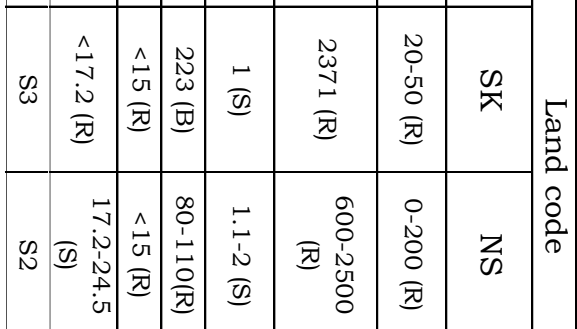

\begin{tabular}{|c|c|c|c|c|c|c|c|}
\hline & 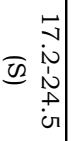 & $\begin{array}{l}\hat{\hat{v}} \\
\frac{\hat{v}}{x}\end{array}$ & 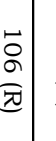 & $\begin{array}{l}\text { in } \\
\text { त्र }\end{array}$ & 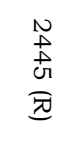 & 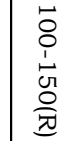 & $\tilde{\varphi}$ \\
\hline N & 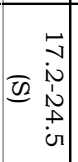 & $\mid \begin{array}{l}\hat{\hat{v}} \\
\overline{0} \\
\underline{\sigma}\end{array}$ & $\begin{array}{l}\overrightarrow{0} \\
0 \\
0 \\
\end{array}$ & 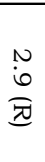 & $\begin{array}{l}\vec{\infty} \\
\omega \\
\widetilde{\omega} \\
\underline{0}\end{array}$ & $\begin{array}{l}\text { No } \\
0 \\
\text { d } \\
\text { On } \\
\underline{W}\end{array}$ & 常 \\
\hline$\tilde{\omega}$ & $\begin{array}{l}\hat{\vec{N}} \\
\hat{N} \\
\tilde{D}\end{array}$ & $\mid \begin{array}{l}\hat{\hat{U}} \\
\overrightarrow{\mathrm{r}} \\
\underline{\underline{\pi}}\end{array}$ & 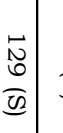 & $\overrightarrow{\widetilde{\theta}}$ & 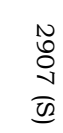 & $\begin{array}{l}\text { i } \\
\text { N } \\
8 \\
\text { त्र }\end{array}$ & 莃 \\
\hline
\end{tabular}


Penilaian beberapa sistem evaluasi lahan yang telah eksisting untuk tanaman karet
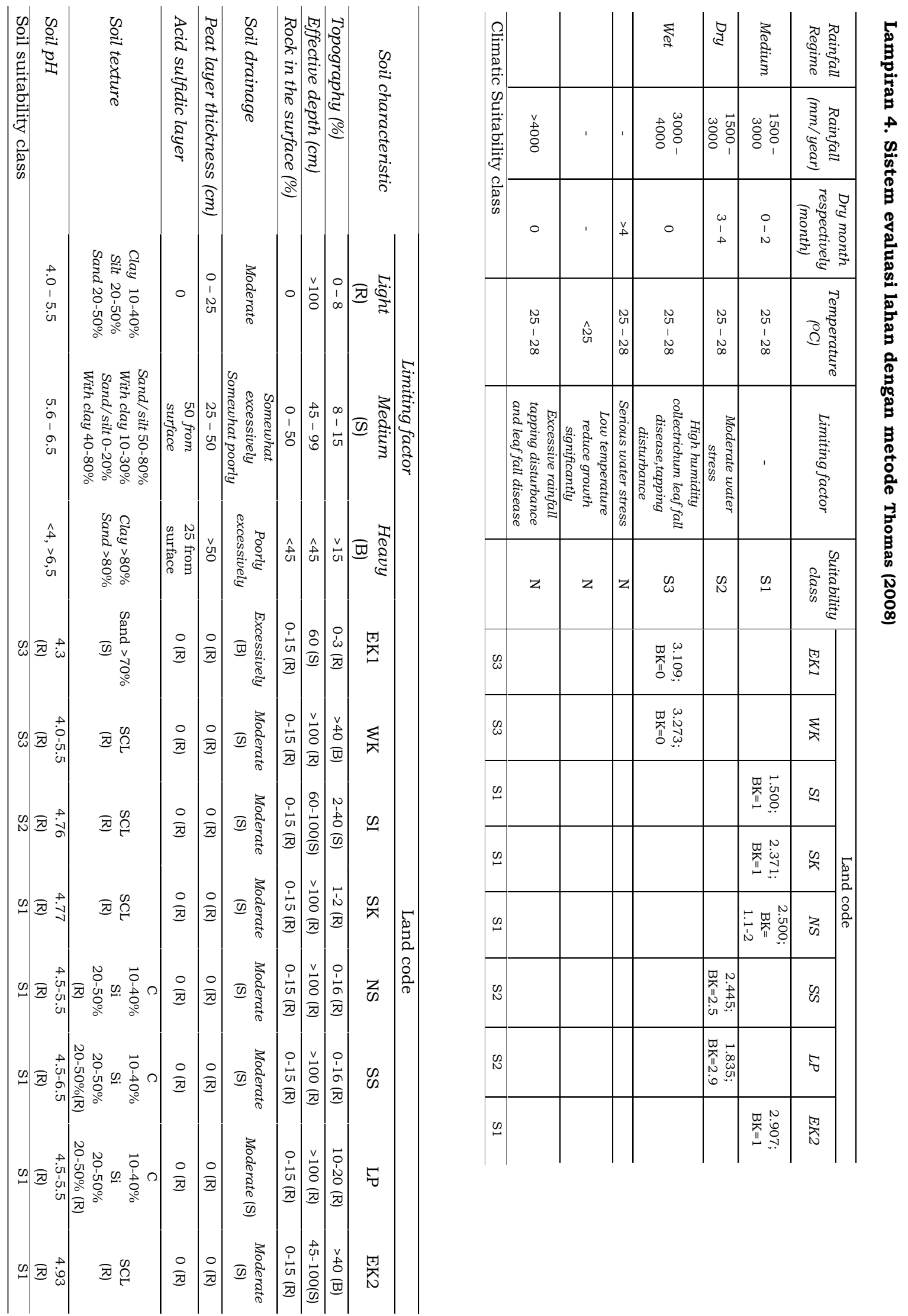
Keterangan untuk lampiran 2, 3 dan 4 :

1. Kesesuaian iklim dan tanah pada dalam sistem evaluasi Sugiyanto (1998) dan Thomas (2008) ditentukan dengan aturan sebagai berikut : Lahan sesuai (S1) adalah lahan dengan maksimal 1 pembatas medium; lahan cukup sesuai (S2) adalah lahan dengan maksimal 2 pembatas medium; Lahan kurang sesuai/sesuai marginal (S3) adalah lahan dengan 2 atau lebih pembatas medium dan atau 1 pembatas berat; Lahan tidak sesuai (N) adalah lahan dengan 2 atau lebih pembatas berat.

2. Untuk sistem evaluasi lahan Sugiyanto (1987); Sugiyanto (1998) dan Thomas (2008), kelas kesesuaian lahan diperoleh dengan cara mengkombinasikan antara kesesuaian iklim dan kesesuaian tanah dengan mengacu pada tabel di bawah ini

\begin{tabular}{|c|c|c|c|c|}
\hline \multirow[b]{2}{*}{$\begin{array}{l}\text { Kesesuaian iklim } \\
\text { Climate suitability }\end{array}$} & \multicolumn{4}{|c|}{$\begin{array}{l}\text { Kesesuaian tanah } \\
\text { Soil suitability }\end{array}$} \\
\hline & $\begin{array}{l}\text { Sesuai } \\
\text { Suitable } \\
\text { (S1) }\end{array}$ & $\begin{array}{l}\text { Cukup sesuai } \\
\text { Moderately } \\
\text { suitable } \\
\text { (S2) }\end{array}$ & $\begin{array}{l}\text { Sesuai Marginal } \\
\text { Marginally } \\
\text { suitable } \\
\text { (S3) }\end{array}$ & $\begin{array}{c}\text { Tidak } \\
\text { Sesuai } \\
\text { Not suitable } \\
\text { (N) }\end{array}$ \\
\hline $\begin{array}{l}\text { Sesuai } \\
\text { Suitable } \\
\text { (S1) }\end{array}$ & $\mathrm{S} 1$ & $\mathrm{~S} 1$ & S2 & S3 \\
\hline $\begin{array}{l}\text { Cukup sesuai } \\
\text { Moderately suitable } \\
\text { (S2) }\end{array}$ & $\mathrm{S} 2$ & S2 & S2 & S3 \\
\hline $\begin{array}{l}\text { Sesuai marginal } \\
\text { Marginally suitable } \\
\text { (S3) }\end{array}$ & S3 & S3 & S3 & $\mathrm{N}$ \\
\hline $\begin{array}{l}\text { Tidak sesuai } \\
\text { Not suitable } \\
\text { (N) }\end{array}$ & $\mathrm{N}$ & $\mathrm{N}$ & $\mathrm{N}$ & $\mathrm{N}$ \\
\hline
\end{tabular}

Catatan kelas tekstur :

CL (klei berloam, Clay Loam), SCL (loam klei pasiran, Sandy Clay Loam), SiCL (loam klei debuan, Silty Clay Loam), L (loam), C (Clay), SL (loam pasiran, sandy Loam), S (Pasir, Sand), Si (Debu, Silt), SiL (loam debuan, Silty Loam), LS (Pasir berloam, loamy sand) 
Lampiran 5. Sistem evaluasi lahan dengan metode Puslittanak (1997)

\begin{tabular}{|c|c|c|c|c|c|c|c|c|c|c|c|c|c|}
\hline \multirow{2}{*}{$\begin{array}{c}\text { Land } \\
\text { characteristic }\end{array}$} & \multicolumn{5}{|c|}{ Land suitability class } & \multicolumn{8}{|c|}{ Land code } \\
\hline & $\mathrm{S} 1$ & $\mathrm{~S} 2$ & S3 & $\mathrm{N} 1$ & $\mathrm{~N} 2$ & EK1 & WK & S1 & SK & NS & SS & LP & EK2 \\
\hline \multicolumn{14}{|c|}{ Temperature $\left({ }^{\circ} \mathrm{C}\right)$ at } \\
\hline Yearly average & $26-30$ & $\begin{array}{l}>30-34 \\
22-<26 \\
\end{array}$ & $\begin{array}{c}\mathrm{Td} \\
22-<24 \\
\end{array}$ & & $\begin{array}{l}>34 \\
<22 \\
\end{array}$ & $\begin{array}{c}26-30 \\
\text { (S1) } \\
\end{array}$ & $\begin{array}{c}26-30 \\
(\mathrm{~S} 1) \\
\end{array}$ & $\begin{array}{c}26-30 \\
\text { (S1) } \\
\end{array}$ & $\begin{array}{c}26-30 \\
\text { (S1) } \\
\end{array}$ & $\begin{array}{c}26-30 \\
(\mathrm{~S} 1)\end{array}$ & $\begin{array}{c}26-30 \\
\text { (S1) } \\
\end{array}$ & $\begin{array}{c}26-30 \\
\text { (S1) } \\
\end{array}$ & $\begin{array}{c}26-30 \\
(\mathrm{~S} 1)\end{array}$ \\
\hline \multicolumn{14}{|c|}{ Water availability $(\mathrm{w})$} \\
\hline $\begin{array}{l}\text { Dry month } \\
\text { (rainfall }<75 \mathrm{~mm})\end{array}$ & $1-2$ & & $>2-4$ & & $\begin{array}{l}>4 \\
<1 \\
\end{array}$ & & & $\begin{array}{c}0 \\
(\mathrm{~N} 2)\end{array}$ & $\begin{array}{c}1 \\
(\mathrm{~S} 1)\end{array}$ & $\begin{array}{c}1.1-2 \\
(\mathrm{~S} 3) \\
\end{array}$ & $\begin{array}{l}2.5 \\
\text { (S3) }\end{array}$ & $\begin{array}{l}2.5 \\
\text { (S3) } \\
\end{array}$ & $\begin{array}{c}1 \\
(\mathrm{~S} 1) \\
\end{array}$ \\
\hline $\begin{array}{l}\text { Rainfall } \\
(\mathrm{mm} / \text { year) }\end{array}$ & $\begin{array}{l}2500- \\
3000\end{array}$ & $\begin{array}{c}>3000- \\
3500 \\
2000- \\
<2500 \\
\end{array}$ & $\begin{array}{c}>3500- \\
4000 \\
1500- \\
<2000 \\
\end{array}$ & $\mathrm{Td}$ & $\begin{array}{l}>4000 \\
<1500\end{array}$ & $\begin{array}{l}3.109 \\
\text { (S2) }\end{array}$ & $\begin{array}{l}3.273 \\
\text { (S2) }\end{array}$ & $\begin{array}{c}1.440 \\
(\mathrm{~N} 2)\end{array}$ & $\begin{array}{c}2.371 \\
(\mathrm{~S} 2)\end{array}$ & $\begin{array}{c}1.600 \\
- \\
2.500 \\
\text { (S3) }\end{array}$ & $\begin{array}{c}2.445 \\
(\mathrm{~S} 1)\end{array}$ & $\begin{array}{l}1.835 \\
\text { (S3) }\end{array}$ & $\begin{array}{l}2.907 \\
\text { (S1) }\end{array}$ \\
\hline \multicolumn{14}{|c|}{ Root area $(r)$} \\
\hline Soil drainage & Moderate & $\begin{array}{c}\text { Somewhat } \\
\text { excessively } \\
\text { somewhat } \\
\text { poorly }\end{array}$ & excessively & $\begin{array}{c}\text { Poorly, } \\
\text { very } \\
\text { excessively }\end{array}$ & $\begin{array}{l}\text { Very } \\
\text { poorly }\end{array}$ & $\begin{array}{c}\text { Exces } \\
\text { sively } \\
(\mathrm{S} 2) \\
\end{array}$ & $\begin{array}{l}\text { Mode- } \\
\text { rate } \\
(\mathrm{S} 1) \\
\end{array}$ & $\begin{array}{l}\text { Mode- } \\
\text { rate } \\
(\mathrm{S} 1) \\
\end{array}$ & $\begin{array}{c}\text { Mode- } \\
\text { rate } \\
(\mathrm{S} 1) \\
\end{array}$ & $\begin{array}{l}\text { Mode- } \\
\text { rate } \\
(\mathrm{S} 1) \\
\end{array}$ & $\begin{array}{l}\text { Mode- } \\
\text { rate } \\
(\mathrm{S} 1) \\
\end{array}$ & $\begin{array}{l}\text { Mode- } \\
\text { rate } \\
(\mathrm{S} 1) \\
\end{array}$ & $\begin{array}{c}\text { Mode- } \\
\text { rate } \\
\text { (S1) } \\
\end{array}$ \\
\hline Soil texture & $\begin{array}{c}\mathrm{SL}, \mathrm{L}, \mathrm{SCL} \\
\mathrm{SiL}, \mathrm{Si}, \mathrm{CL} \\
\mathrm{SiCL} \\
\end{array}$ & LS, SC & $\mathrm{SiC}, \mathrm{StrC}$ & $\mathrm{Td}$ & $\begin{array}{l}\text { Gravel, } \\
\text { sand, } \\
\text { massive } \\
\text { clay }<50\end{array}$ & $\begin{array}{c}\text { Sand } \\
>70 \% \\
\text { (N2) }\end{array}$ & $\begin{array}{l}\mathrm{SCL} \\
(\mathrm{S} 1)\end{array}$ & $\begin{array}{l}\mathrm{SCL} \\
(\mathrm{S} 1)\end{array}$ & $\begin{array}{l}\mathrm{SCL} \\
\text { (S1) }\end{array}$ & $\begin{array}{l}\text { SCL } \\
\text { (S1) }\end{array}$ & $\begin{array}{l}\mathrm{SCL} \\
\text { (S1) }\end{array}$ & $\begin{array}{l}\mathrm{SCL} \\
\text { (S1) }\end{array}$ & $\begin{array}{l}\mathrm{SCL} \\
\text { (S1) }\end{array}$ \\
\hline $\begin{array}{l}\text { Effective depth } \\
(\mathrm{cm})\end{array}$ & $>100$ & $75-100$ & $50-75$ & & $<50$ & $\begin{array}{c}60 \\
(\mathrm{~S} 3)\end{array}$ & $\begin{array}{l}>100 \\
(\mathrm{~S} 1)\end{array}$ & $\begin{array}{l}60- \\
100 \\
(\mathrm{~S} 2) \\
\end{array}$ & $\begin{array}{l}>100 \\
(\mathrm{~S} 1)\end{array}$ & $\begin{array}{l}>100 \\
(\mathrm{~S} 1)\end{array}$ & $\begin{array}{l}>100 \\
(\mathrm{~S} 1)\end{array}$ & $\begin{array}{c}>100 \\
(\mathrm{~S} 1)\end{array}$ & $\begin{array}{l}45- \\
100 \\
(\mathrm{~S} 3) \\
\end{array}$ \\
\hline \multicolumn{14}{|c|}{ Peat } \\
\hline Maturity & - & sapric & hemic & $\begin{array}{l}\text { hemic- } \\
\text { fibric }\end{array}$ & fibric & - & - & - & - & - & - & - & - \\
\hline Thickness & - & $<100$ & $100-<150$ & $>150-200$ & $>200$ & - & - & - & - & - & - & - & - \\
\hline \multicolumn{14}{|c|}{ Nutrion resention (f) } \\
\hline $\mathrm{CEC}$ & ĚL öŇèTt & low & Very low & & & $\begin{array}{l}\text { Low } \\
\text { (S2) }\end{array}$ & $\begin{array}{l}\text { Mediu } \\
\mathrm{m}(\mathrm{S} 1)\end{array}$ & $\begin{array}{l}\text { Low } \\
\text { (S2) }\end{array}$ & $\begin{array}{l}\text { Low } \\
\text { (S2) }\end{array}$ & $\begin{array}{l}\text { Low } \\
\text { (S2) }\end{array}$ & $\begin{array}{l}\text { Low } \\
\text { (S2) }\end{array}$ & $\begin{array}{l}\text { Low } \\
\text { (S2) }\end{array}$ & $\begin{array}{l}\text { Low } \\
\text { (S2) } \\
\end{array}$ \\
\hline $\mathrm{pH}$ tanah & $4.5-5.5$ & $\begin{array}{l}>5.5-6.5 \\
4.0-4.5\end{array}$ & $\begin{array}{c}>5.5-7.5 \\
3.5-4.0\end{array}$ & $>7.5-8.5$ & $\begin{array}{l}>8.5 \\
<3.5\end{array}$ & $\begin{array}{l}4.3 \\
\text { (S1) }\end{array}$ & $\begin{array}{l}4.0- \\
5.5 \\
\text { (S1) }\end{array}$ & $\begin{array}{l}4.76 \\
(\mathrm{~S} 1)\end{array}$ & $\begin{array}{l}4.77 \\
(\mathrm{~S} 1)\end{array}$ & $\begin{array}{c}4.5- \\
5.5 \\
(\mathrm{~S} 1) \\
\end{array}$ & $\begin{array}{l}4.5- \\
5.5 \\
\text { (S1) } \\
\end{array}$ & $\begin{array}{l}4.5- \\
5.5 \\
\text { (S1) }\end{array}$ & $\begin{array}{l}4.93 \\
\text { (S1) }\end{array}$ \\
\hline \multicolumn{14}{|c|}{ Salinity (c) } \\
\hline $\begin{array}{l}\text { Salinity } \\
\left(\mathrm{mmhos} / \mathrm{cm}^{2}\right)\end{array}$ & $<1$ & $1-3$ & $>3-4$ & $>4-5$ & $>5$ & $\begin{array}{l}<1 \\
(\mathrm{~S} 1) \\
\end{array}$ & $\begin{array}{l}<1 \\
(\mathrm{~S} 1) \\
\end{array}$ & $\begin{array}{l}<1 \\
(\mathrm{~S} 1) \\
\end{array}$ & $\begin{array}{l}<1 \\
(\mathrm{~S} 1) \\
\end{array}$ & $\begin{array}{l}<1 \\
\text { (S1) } \\
\end{array}$ & $\begin{array}{l}<1 \\
(\mathrm{~S} 1) \\
\end{array}$ & $\begin{array}{l}<1 \\
(\mathrm{~S} 1) \\
\end{array}$ & $\begin{array}{l}<1 \\
(\mathrm{~S} 1) \\
\end{array}$ \\
\hline \multicolumn{14}{|c|}{$\operatorname{Toxicity}(\mathrm{x})$} \\
\hline Al saturation (\%) & & & & & & - & - & - & - & - & - & - & - \\
\hline $\begin{array}{l}\text { Depth of pyrite } \\
\text { (cm) }\end{array}$ & $>200$ & $130-200$ & $80-<130$ & $<30$ & & - & - & - & - & - & - & - & - \\
\hline \multicolumn{14}{|c|}{ Avaible nutrient ( $n$ ) } \\
\hline Total N & ĚL öŇèTt & low & Very low & $\mathrm{Td}$ & $\mathrm{Td}$ & $\begin{array}{l}\text { Very } \\
\text { low } \\
\text { (S3) }\end{array}$ & $\begin{array}{l}\text { Very } \\
\text { low } \\
\text { (S3) }\end{array}$ & $\begin{array}{l}\text { Low } \\
\text { (S2) }\end{array}$ & $\begin{array}{l}\text { Low } \\
\text { (S2) }\end{array}$ & $\begin{array}{l}\text { Low } \\
\text { (S2) }\end{array}$ & $\begin{array}{l}\text { Low } \\
\text { (S2) }\end{array}$ & $\begin{array}{l}\text { Very } \\
\text { low } \\
\text { (S3) }\end{array}$ & $\begin{array}{l}\text { Very } \\
\text { low } \\
\text { (S3) }\end{array}$ \\
\hline $\mathrm{P}_{2} \mathrm{O}_{5}$ & ĚĔè $\breve{E}$ & medium & Low & & & $\begin{array}{l}\text { Very } \\
\text { low } \\
\text { (S3) }\end{array}$ & $\begin{array}{l}\text { Very } \\
\text { low } \\
\text { (S3) }\end{array}$ & $\begin{array}{l}\text { Low } \\
\text { (S3) }\end{array}$ & $\begin{array}{l}\text { Low } \\
\text { (S3) }\end{array}$ & $\begin{array}{l}\text { Low } \\
\text { (S3) }\end{array}$ & $\begin{array}{l}\text { Low } \\
\text { (S3) }\end{array}$ & $\begin{array}{l}\text { Low } \\
\text { (S3) }\end{array}$ & $\begin{array}{l}\text { Very } \\
\text { low } \\
\text { (S3) } \\
\end{array}$ \\
\hline $\mathrm{K}_{2} \mathrm{O}$ & Ěiŏơ & Very low & & & & $\begin{array}{l}\text { Very } \\
\text { low } \\
\text { (S2) }\end{array}$ & $\begin{array}{l}\text { Very } \\
\text { low } \\
\text { (S2) }\end{array}$ & $\begin{array}{l}\text { Low } \\
\text { (S1) }\end{array}$ & $\begin{array}{l}\text { Low } \\
\text { (S1) }\end{array}$ & $\begin{array}{l}\text { Low } \\
\text { (S1) }\end{array}$ & $\begin{array}{l}\text { Low } \\
\text { (S1) }\end{array}$ & $\begin{array}{l}\text { Low } \\
\text { (S1) }\end{array}$ & $\begin{array}{l}\text { Very } \\
\text { low } \\
\text { (S2) } \\
\end{array}$ \\
\hline \multicolumn{14}{|c|}{ Mechanization potency } \\
\hline Slope $(\%)$ & $<8$ & $8-15$ & $>15-25$ & $>25-45$ & $>45$ & $\begin{array}{l}0-3 \\
\text { (S1) }\end{array}$ & $\begin{array}{l}>40 \\
\text { (N1) }\end{array}$ & $\begin{array}{l}2-40 \\
\text { (S3) }\end{array}$ & $\begin{array}{l}1-2 \\
\text { (S1) }\end{array}$ & $\begin{array}{l}0-1.5 \\
\text { (S1) }\end{array}$ & $\begin{array}{c}0-1.5 \\
\text { (S1) }\end{array}$ & $\begin{array}{c}10-20 \\
\text { (S3) } \\
\end{array}$ & $\begin{array}{l}>45 \\
\text { (N2) } \\
\end{array}$ \\
\hline $\begin{array}{l}\text { Rock in the } \\
\text { surface }(\%)\end{array}$ & $<5$ & $5-10$ & $>10-15$ & $>15-25$ & $>25$ & $\begin{array}{l}<5 \\
(\mathrm{~S} 1) \\
\end{array}$ & $\begin{array}{l}<5 \\
(\mathrm{~S} 1) \\
\end{array}$ & $\begin{array}{l}<5 \\
\text { (S1) } \\
\end{array}$ & $\begin{array}{l}<5 \\
(\mathrm{~S} 1) \\
\end{array}$ & $\begin{array}{c}<5 \\
\text { (S1) } \\
\end{array}$ & $\begin{array}{c}<5 \\
(\mathrm{~S} 1) \\
\end{array}$ & $\begin{array}{c}<5 \\
(\mathrm{~S} 1) \\
\end{array}$ & $\begin{array}{c}<5 \\
(\mathrm{~S} 1) \\
\end{array}$ \\
\hline Rock (\%) & $<5$ & $5-10$ & $>10-15$ & $>15-25$ & $>25$ & $\begin{array}{l}<5 \\
\text { (S1) }\end{array}$ & $\begin{array}{l}<5 \\
(\mathrm{~S} 1)\end{array}$ & $\begin{array}{l}<5 \\
\text { (S1) }\end{array}$ & $\begin{array}{l}<5 \\
(\mathrm{~S} 1)\end{array}$ & $\begin{array}{l}<5 \\
(\mathrm{~S} 1) \\
\end{array}$ & $\begin{array}{l}<5 \\
(\mathrm{~S} 1)\end{array}$ & $\begin{array}{l}<5 \\
(\mathrm{~S} 1) \\
\end{array}$ & $\begin{array}{l}<5 \\
(\mathrm{~S} 1)\end{array}$ \\
\hline Erosion level (e) & Very low & low & medium & high & $\begin{array}{l}\text { Very } \\
\text { high }\end{array}$ & $\begin{array}{l}\text { Low } \\
\text { (S3) }\end{array}$ & $\begin{array}{l}\text { Mediu } \\
m \text { (S3) }\end{array}$ & $\begin{array}{l}\text { High } \\
\text { (N1) }\end{array}$ & $\begin{array}{l}\text { Low } \\
\text { (S2) }\end{array}$ & $\begin{array}{l}\text { Mediu } \\
\text { m } \\
\text { (S3) } \\
\end{array}$ & $\begin{array}{l}\text { Mediu } \\
\quad m \\
\text { (S3) }\end{array}$ & $\begin{array}{c}\text { Mediu } \\
\text { m } \\
\text { (S3) }\end{array}$ & $\begin{array}{l}\text { High } \\
\text { (N1) }\end{array}$ \\
\hline Flood (b) & FO & $\mathrm{F} 1$ & $\mathrm{~F} 2$ & F3 & F4 & - & - & - & - & - & - & - & - \\
\hline Land Suitability & & & & & & S3 & N1 & $\mathrm{N} 2$ & S2 & S3 & S3 & S3 & $\mathrm{N} 2$ \\
\hline
\end{tabular}

